time." Historical time allows for project: it is a neutral and homogeneous temporal medium in which things exist and events take place as if on a road stretching to infinity. This belief, which has dominated Western thought since the Renaissance, is still at the heart of Victorian narrative. Rhythmic time, on the contrary, is an "exploratory repetition" coextensive with the event and which the subject cannot distance itself from, and therefore "any ' $I$ ' or ego or cogito exists only for the same duration and then disappears [...] or undergoes transformation into some new state of being" (Sequel 53). This postmodern view of temporality is, according to the author, analogous to medieval conceptions. In between, Ermarth says, there is the humanist historical temporality, still latent in nineteenth-century narrative, which she cleverly analyzes in The English Novel in History: 1840-1895.

It is in the latter book's Chapter Four, "Dilemmas of Difference," that Ermarth's feminist standpoint becomes most visible. Here the author treats issues such as class, gender, and other varieties of cultural difference, and the problems they posited in the nineteenth century to the democratic agendas of some realms of English cultural discourse such as narrative fiction and philosophy. This last chapter assumes the concepts of nature, time, and society explained in the other three, and in this sense culminates the argument expounded all along the book and conveys the ideological outlook that dominates Ermarth's approach, which is, as has been anticipated, that of postmodern feminist critical theory.

The way the book is structured - with all four chapters developing an argument, and all of them also firstly stating general ideas which are in turn illustrated-does not favour browsing for particular points, as we are warned in the Preface. This, along with the difficulty of some of the matters discussed, will not contribute to making the book popular among students. It is a book written for the specialist and asks to be read from the beginning to the end, if the reader is to grasp the main argumentative lines.

Those of us who do not possess Prof. Ermarth's erudition cannot help but being impressed by the wealth of sources and information that she utilizes, and even more by the intelligent, original, and insightful way in which this conceptual apparatus is combined to produce a book which is a strong personal statement, both critically and politically. As such, it invites discussion and is bound to generate fruitful controversy if it receives the scholarly attention that, as a doubtless major study of the period in question, it clearly deserves.

Ángel Pérez Vázquez

Román Álvarez \& M. Carmen África Vidal, eds. Translation Power Subversion. Topics in Translation Series, Clevedon, Philadelphia, Adelaide: Multilingual Matters, 1996, vi + 157 pp.

Translation studies represent one of the most attractive fields of research at the moment. It has the advantage of being a relatively new area. Everybody knows that translation dates from thousands of years and has been an essential character in lots of 
historical and cultural events, but the truth is studies on the technique or the process of translation have been restricted for centuries to impressionistic approaches which did not even give enough information to elaborate a set of norms to be applied. Someone simply said they liked or disliked somebody else's translation, an assessment which was, of course, based on questions of taste and had no scientific foundations whatsoever. Translation was seen either as a necessary but disagreeable procedure which had nothing to do with art or linguistics or as a piece of literary recreation which could be liked or not according to whimsical criteria and, of course, could not be described as following any kind of system. This situation has fortunately changed during the last decades and this compilation of articles collected by R. Álvarez and M.A.C. Vidal is a good example of it.

Before I refer to the contents of this volume in more detail I would like to make some comments on the field of translation theory or translation studies. I think it is essential to underline that the turning point in the evolution of this discipline is the change from the vision of translation as a product to the vision of translation as a process. This means a radical transformation and is the marrowbone to the modern theory of translation. There is much more to translation than just replacing words or phrases written in one language with others written in a different language. It is no good looking at a translation as something finished that is going to be praised or rejected, the idea of the one and only correct translation vanishes. R. Álvarez and M.C.A. Vidal express it in the following terms: "...From the eagerness to consider translation as a science or the obsession to give a definitive, prescriptive and sole version of a text, we have moved on to a descriptive outlook which likewise, whether we like it or not, is political" (1). What we are dealing with is, therefore, a very complex intellectual activity which lends itself to different strategies and techniques, none of which can be discarded beforehand. Furthermore, as Álvarez and Vidal suggest above, the study of such techniques and the complexity of translation has also shown aspects such as the effects of translating in a particular way, the impact the translator's choice can have on the readers of the target language and most important, to what extent that choice is, if you allow me the word, innocent. Susan Bassnett says at the end of her article: "we may not burn translators at the stake (though the attacks on Salman Rushdie's translators show that the translator was certainly not seen as an invisible filter) but we are compelled now to recognize the role they play, I am thinking of aspects such as the political use of translation (manipulation, censorship, etc.) (23).

The volume Translation Power Subversion sheds some light on the aspects mentioned in the preceding paragraph along with other equally interesting topics such as pragmatics and cultural translation to mention just a couple, which have been and are still contributing to enlarge the firing range of the field we refer to as translation studies. As regards pragmatics, E. Alcaraz's article offers us a panorama of the different paradigms that have dominated linguistic research in the present century, namely, structuralism, generativism and finally pragmatics. It is the last of these three that is current at the moment, its importance in the field of translation being paramount, specially as it is the source from which the essential notion of pragmatic equivalence has arisen. This new concept of equivalence, in Alcaraz's words “...has a much wider scope of application than semantic equivalence. It includes not only the analysis and comparison of the textual 
meaning of the same passage written in two different languages, but of all the other textual categories (cohesion, thematization, etc.) that may affect their final perception by the receivers of the two languages..." (107)

Along the lines of the previous reference to pragmatics and the enlarged field of application, it is also equally relevant to underline the role of culture, an aspect which is dealt with in J. Franco, O. Carbonell and E. Gentzler's articles, though from different points of view. Thus, J. Franco tries to define what he calls a CSI (culture-specific item). His conclusion is: “...a CSI does not exist of itself, but as the result of a conflict arising from any linguistically represented reference in a source text which, when transferred to a target language, poses a translation problem due to the non-existence or to the different value (whether determined by ideology, usage, frequency, etc.) of the given item in the target language culture" (57). Franco's analysis of three translations of The Maltese Falcon also gives the reader an insight into the workings of the system of cultural translation.

O. Carbonell concentrates on the problems of translation when two mutually 'exotic' cultures are involved. He tells us that in this kind of text "meaning is not located in a source culture or a target culture in an univocal signifying movement; rather, it is being created endlessly in a third cultural space of growing conflict and complexity" (90). Translation, therefore, "trascends the closed circularity of mere imitation ... Translation is a movement 'beyond', establishing a dialectics between here and there, now and then, us and them" (93).

E. Gentzler offers the reader an interesting article on the role of translation as a counter-cultural force through its use in the American journal The Fifties. This article underlines the fact that translation is a means of creating new literary or cultural forms, as is shown by Robert Bly, one of the editors of the journal, whose "work in translation during the fifties played an important role in the development of the new form of poetry" (135) and whose case "supports the thesis that translations played a key role in causing the ensuing cultural crisis" (135).

The last two articles I will refer to are those written by A. Léfevere and T. Hermans. The former concentrates on establishing a relationship between what he considers two ways of rewriting literary texts, namely, translation and the compilation of anthologies. He describes them both in the following terms: "If a translation provides its readers with an image of its original ... the compilation of anthologies, tries to provide its readers/students with an image of literature, a period in a literature, a type, such as drama in general..." (139). He illustrates his reference to anthologies with an analysis of those published in the United States between 1900 and 1988 and reminds the reader of the fact that anthologies are often the first contact readers have with literature and are equally a reflection of the literary canon of their time.

Finally, T. Hermans carries out an exhaustive study of norms in translation. As Hermans puts it "one of the major tasks of the researcher wishing to account for translation as a social practice consists in identifying and interpreting the norms which governed the translator's choices and decisions" (39). Hermans' study shows us that this is by no means an easy task if we bear in mind that we must deal with different cultures and our description of norms will be nothing but an always relatively biased 
interpretation, which leads the reader back to some of the main worries in current research in the field in translation, namely, the importance of politics, the national and international state of affairs, the preeminence of some cultures over others, and so on. The study of translation is therefore, the study of a whole galaxy of factors, as is shown in the excellent group of articles written by an illustrious group of researchers and collected by R. Álvarez and M.A.C. Vidal in Translation Power Subversion.

Víctor Manuel Pina Medina

\section{Michael D. Bristol. Big-time Shakespeare. London: Routledge 1996.}

This is an interesting analysis of the development of Shakespeare's work in the past and present industry of entertainment, which brings together literary, sociological and even economic perspectives. The book is organised in two sections (under the headings The supply side of culture and The pathos of Western modernity) preceded by a twenty-five page introduction.

The initial attitude of the author, Prof. Michael D. Bristol, seems to be to reveal the use of the playwright's image as a potentially marketable decoy for products that are, if anything, only obliquely related to it; from films loosely based on his plays all the way down to credit cards or bank notes that carry his portrait. A business-like manoeuvre with a cultural alibi. However, the first pages of this book err on the side of trivialisation as well. A comparison of Shakespeare to The Beatles, Elvis Presley or Mick Jagger (in a paragraph which is also quoted in the very colourful back cover) looks very much like an 'epater l'Academie' strategy which many may think we have had enough of.

Fortunately, after this flashy introduction, the author gets down to more serious business. The first part of the book opts for a sociological approach to Shakespeare's impact on Western civilization. An interesting conception of his everlasting success as a conflation of the contributions of editors, directors, actors and other members of professional and academic circles throughout the last four centuries gives way to a biographical reference to the most outstanding ones. From Restoration show business entrepreneur William Davenant to 18 th century actor and theatre manager David Garrick; publisher Jacob Tonson and his rewriting-Shakespeare conflicts with Alexander Pope and the reputed scholar Lewis Theobald; with the latest conflictive step being Kenneth Branagh's current cinematic simplifications. The economic and social conditions of the culture entertainment industry do not seem to have changed that much after all this time.

Several critical issues are at stake here concerning Shakespeare's massive appeal: the way certain literary specialists reject his versatility at crossing the bridge between popular and high culture (which do not have to be mutually exclusive); the dialogical relationship between the moment of creation and the period of representation/reception; and the semantic potentiality of his work and how it can be manipulated by subsequent structures of power. Prof. Bristol dismisses the intention of the author as a key factor in establishing meaning, but does not join the poststructuralist mourning either. The text value itself, which is indebted to the author, but also to its multiple readings and performances, determines its unrivalled emancipatory strength. 